\title{
Mortuary design and hazards ${ }^{1}$
}

A committee was set up in November 1959 to investigate the conditions under which necropsy work is carried out, and to report to the Council on any desirable improvements in these conditions.

The committee has circulated questionnaires to pathologists in a number of different areas of the country, and has collected information regarding existing facilities for necropsy work in general hospitals, teaching hospitals, and public mortuaries. Views have also been sought on the need for improving mortuary facilities, and on desirable standards for these three types of mortuary unit. Members of the committee have discussed the subject with numerous pathologists, with hospital architects, and with other interested parties, including coroners and medical officers of health. The present memorandum presents the committee's conclusions and recommendations.

\section{RESULT OF THE SURVEY}

The committee was impressed by the extremely varied standards existing in different hospital departments and public mortuaries throughout the country (Figs. 1 and 2). Some mortuary units are spacious and well-designed and are well-staffed and equipped with every facility for efficient work. A large number, however, are cramped and awkward, with few facilities, and the committee feels that there is a general need for improvement. As new hospitals are built, this improvement is gradually being effected by the provision of modern and welldesigned mortuary units, but there is urgent and very considerable scope for the improvement of mortuary units in existing hospitals: the same is true with regard to public mortuaries.

The committee feels that information and general guidance should be available for those pathologists who have the opportunity either of designing new units or of improving old ones: it hopes that such information will stimulate many pathologists to look afresh at their own mortuary facilities and see what can be done to improve them.

Many pathologists have expressed dissatisfaction with staffing arrangements in mortuaries, and the committee has some comments to make on this subject.

${ }^{1}$ Report to the Council of the Association of Clinical Pathologists of the Committee on Mortuary Design and Hazards (F. E. Camps, chairman, G. Stewart Smith, A. Dick, and H. H. Sissons, secretary).
The question of the joint use of mortuaries by hospital and coroners' pathologists is also considered.

\section{DESIGN AND EQUIPMENT OF MORTUARIES AND POST-MORTEM ROOMS}

Although general considerations of design and equipment apply equally to various types of mortuary unit, both hospital and public, there are differences of emphasis and detail, and we have thought it best to set out our views under headings relating to the large general hospital, the smaller hospital, the teaching hospital, and the public mortuary. It will be clear, however, that much of what we have to say regarding hospital units applies to public mortuaries.

LARGE GENERAL HOSPITAL In designing a new hospital it is desirable to incorporate the mortuary unit, including the post-mortem room, in the main structure. Access to the unit is of great importance, and it should be sited so that there is ready and separate access by the various groups of people concerned (pathologists and other medical staff, staff transferring bodies from wards to mortuary, relatives coming to view bodies, undertakers, etc.). Sometimes there may be conflict between these different requirements, but in a modern hospital block good access is often most readily achieved by siting the mortuary unit in the basement. There can be separate routes of entry within the hospital for bodies, visiting relatives, and medical staff. An external undertakers' entrance, screened from wards and outside roads, can be provided.

In existing hospitals, the mortuary unit is usually a separate building, and this may sometimes be an advantage if it is to be used jointly by the hospital and local authority (see page 107). Siting and access are still important matters. A separate mortuary unit should have pleasant and dignified surroundings, and should not-as is so often the case-be consigned forever to some remote, inaccessible, and untidy corner of the hospital grounds.

In addition to a general mortuary area equipped with adequate refrigerated body storage, and a suitably sized and equipped post-mortem room, the mortuary unit should include a room for the mortuary attendant, facilities for viewing bodies, and a waitingroom and W.C. for visiting relatives. 


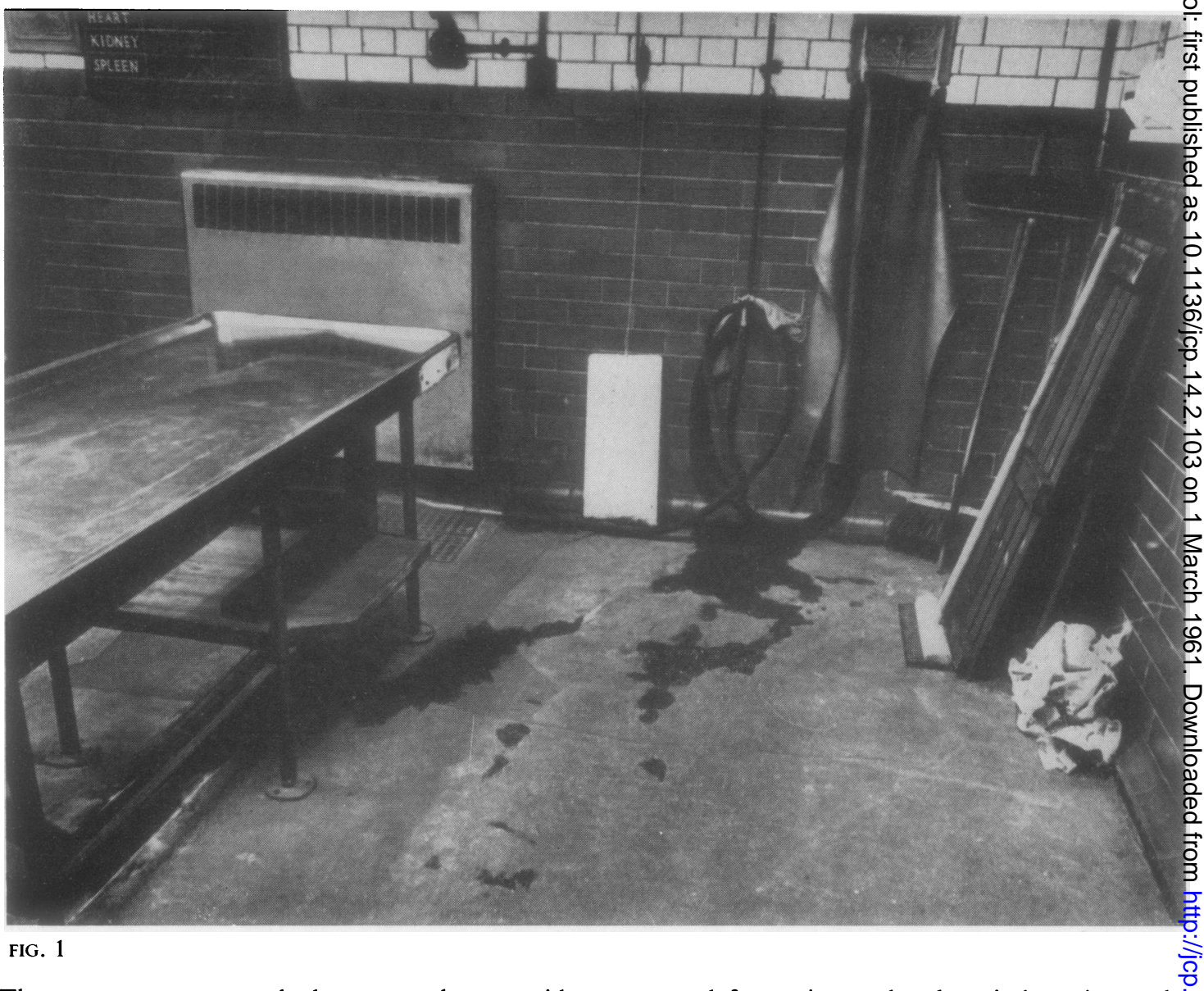

The mortuary area must be large enough to provide space for undertakers; adequate storage space is important. Facilities for washing and gowning should be provided outside the actual post-mortem room, and shower rooms and W.C.s should be available both for pathologists and post-mortem room attendants. If the unit is at a distance from the pathology department, a doctors' room should be provided where reports can be written or dictated. Some pathologists would like such a room, or the pathology department itself, to be linked to the post-mortem room by a two-way inter-communication system, so that reports can be dictated to a secretary or recorded on tape during the course of a necropsy.

An actual 'chapel' for the viewing of bodies is regarded as unnecessary. A simple but quite adequate scheme can consist of a viewing room, separated from part of the mortuary area by a curtained window, the glass of which is tilted from the vertical to avoid reflections. The body to be viewed can be laid out in the mortuary, completely separated from viewers by the window: it can be் isolated from the rest of the mortuary area by. sliding curtains hanging from the ceiling. A separate room to house a body to be viewed is even better again, a glass window should effect complete separation between the body and the viewing relatives.

There is abundant scope for individual planning in the arrangement of the rooms making up the mortuary unit, and this should always be con 0 sidered with the hospital architect. Thought should be given to the different routes by which bodies and various types of personnel move into and out of thes unit: these should overlap as little as possible. Ore no account should there be a common entrance of exit for bodies and visiting relatives. It is mosto undesirable that relatives should have access by ang route to the mortuary area itself or to the post $\frac{\mathbb{Q}}{\Omega}$ mortem room. The mortuary attendant's roon $\mathbb{B}$ should be sited so that he is available to visiting relatives, as well as having ready access to the mortuary area and the post-mortem room. Cono 


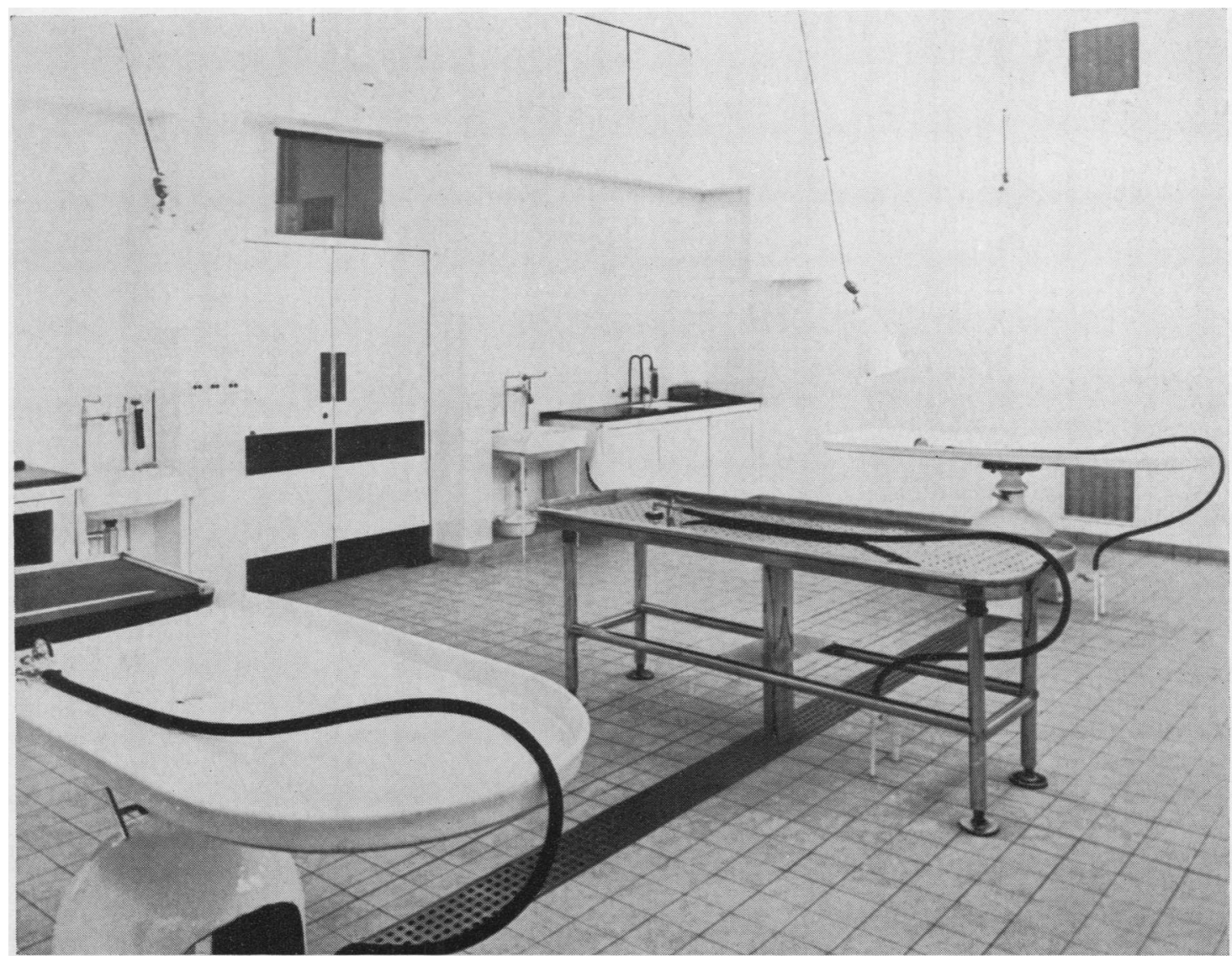

FIG. 2

sultation with the hospital architect and reference to such works as Rosenfeld's 'Hospitals: Integrated Design' (2nd edition, Reinhold, New York, 1951), and 'Studies in the Function and Design of Hospitals', a report of an investigation sponsored by the Nuffield Provincial Hospitals Trust and the University of Bristol (Oxford University Press, 1955), are suggested for those concerned with the design of a new unit.

Body storage Refrigerated body storage is of course essential. It should be provided on a generous scale, particularly when a mortuary is to be used for both hospital and outside coroners' cases. A mortuary where 500 necropsies a year are carried out should have storage space for at least 18 bodies: storage space for 24 to 30 is usually adequate for 1,000 necropsies a year.

Post-mortem room Adequate space is essential: the committee feels that a poor standard of work is more often due to cramped conditions than to any other single factor. A post-mortem room dealing with 500 necropsies a year should, if possible, have three post-mortem tables, and its floor area should be not less than 500 sq. ft. A post-mortem room with four tables should have a floor area of approximately $800 \mathrm{sq}$. ft. If air conditioning is not available, the post-mortem room should be of generous height (12 to $15 \mathrm{ft}$.) and there should be adequate ventilation. In any case, the whole unit should be fly proof.

Air conditioning is highly desirable, and should certainly be considered when any new unit is planned. It should provide a high rate of change of air, it should not involve recirculation, and it is important that air extracted from the mortuary is not delivered to other parts of the hospital, even indirectly. In this connexion, the mortuary unit should not be directly in communication with a lift shaft or with any other shaft which has openings on other floors.

Lighting is extremely important. Good daylight is satisfactory, but the situation of the post-mortem room may make it impossible to provide this. If the main sources of illumination is by artificial lighting this needs careful planning. The general level 
of illumination should be approximately 30 lumens per sq. ft., with additional lighting over postmortem tables and dissecting benches. Provision should be made for some form of moveable lighting to examine cavities. The pros and cons of tungsten lighting and fluorescent lighting (natural colour) should be considered: it is difficult to recognize important colour changes (such as that concerned in carbon monoxide poisoning) with some types of artificial lighting. Roof lighting is often a feature of older mortuaries, but roof lights can interfere with the maintenance of an even temperature and need shielding against brilliant sunshine: we feel they are better avoided.

A smooth finish to walls and floors makes for easy maintenance of a high standard of cleanliness. Terrazzo finish has been used in recent years but may crack: modern materials such as polyvinyl chloride (P.V.C.) sheeting can be used to give an impermeable and easily washable surface for both walls and floor with rounded surfaces in all corners. Conduits, pipes, etc. can be located behind flush removable panels. Acoustically absorbent material should be used for the ceiling. Cupboards and other furniture should be plinth-mounted to facilitate washing down.

Plenty of well-illuminated bench space (say $20 \mathrm{ft}$.) should be provided for dissection, weighing of organs, etc., away from the post-mortem tables. It should include several large sink units, fitted with hot and cold water, and the bench top should be of impermeable material, preferably stainless steel. The surface actually used for dissection should be of easily cleaned material such as hard wood. Specimens which are to be preserved for museum mounting should not come in contact with water: the provision of running saline allows the washing of such specimens prior to their fixation. There should be adequate cupboard space (preferably built-in) for instruments, specimen jars, etc. Storage space for clean gowns, boots, aprons, gloves, etc. should be located outside the post-mortem room. A cleaners' cupboard for brooms and other cleaning materials should be provided in the mortuary area: there should also be adequate storage space for clothing of the deceased. Storage space (usually shelving) for fixed specimens should be provided near the post-mortem room, but a mortuary store room is the best way to overcome this difficulty.

In the post-mortem room, balances, blackboard, wall-mounted $x$-ray viewing boxes, and electric saw (reciprocating type) should all be standard equipment: a bandsaw and a portable $x$-ray unit should be available in a separate room, and the post-mortem attendant should be properly trained in the safe use of the latter. While porcelain post-mortem tables are commonly used, stainless steel tables do not chip and can more readily be kept clean. Tables should be provided with running water and with dissecting tables if these are used. Drainage from the table should be by completely enclosed pipesn under the floor. If open floor channels cannot bed avoided they should be covered by rust-proof metaf grids. There should be provision for sterilization of? instruments from potentially infective cases; an $\vec{\rho}$

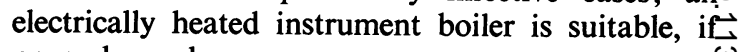
properly used.

Hygiene With adequate space and proper plan ning, the post-mortem room should be as clean and efficient as an operating theatre, and the likelihood of bacterial contamination of staff during a necropsy. should be minimal. As in an operating theatre, the provision of smooth washable surfaces and theo avoidance of wall-mounted pipes and other obstruc- tions can eliminate the accumulation of potentiallys infective dust and dirt. Strong emphasis should always be placed on hygiene in necropsy work. A $\mathrm{A}^{\Im}$ good rule is that no one should enter the post $\overrightarrow{0}$ mortem room without donning gown and boots, and these must be discarded on leaving. A telephone can be provided within the post-mortem room which operates without being touched by hand. Othero comparable measures can easily be instituted in a well-planned unit, but it is important to beop reminded that in existing mortuary units a good standard of hygiene is often made impossible by bad arrangement of rooms and by cramped space $\frac{3}{5}$

The precautions that should be taken to preven the dissemination of tubercle bacilli in the post mortem room have been summarized in a repor to the Public Health Laboratory Service ${ }^{1}$. The report stresses general cleanliness, training of post 3 . mortem attendants, and disinfection of instruments $\hat{\circ}$ dissecting surfaces, protective clothing, etc., after necropsies on tuberculous subjects.

SMALLER HOSPITALS The general emphasis on access. and on good facilities and cleanliness, noted for the larger unit should still apply; because a hospital is small, there is no reason that the standards shoulds be lower. A post-mortem room with one tables (adequate for about 100 necropsies per year) should have a floor area of 300 sq. ft., and should have theo same standards of finish and equipment suggestec $\bar{D}$ for the larger unit. There should be facilities for ${ }^{+}$ washing and gowning outside the post-mortem room, The unit should include refrigerated body storage A hospital carrying out 100 necropsies per year needs space for six bodies, and three is the minimung

${ }^{1 ' P r e c a u t i o n s ~ a g a i n s t ~ t u b e r c u l o u s ~ i n f e c t i o n ~ i n ~ t h e ~ d i a g n o s t i c ~ l a b o r ~} \sigma$ tory', 1958. Bulletin of Ministry of Health and Public Laboratoro Service, 17 January 1958. 
number for any unit where necropsies are performed. However small the unit, there should always be facilities for viewing bodies, together with a waitingroom and W.C. for visiting relatives. The separation of access for doctors, visiting relatives, and for bodies and undertakers is as important in the small unit as in the large one.

TEACHING HOSPITAL The mortuary unit should be similar to that in a large general hospital. Because of the greater number of people likely to be present at necropsies, even more space is required in the post-mortem room itself. For the same reason, considerations of hygiene are of outstanding importance. Students and other onlookers should not enter the actual post-mortem area unless they are gowned and taking part in the examination: a tiered gallery with separate entrance should be provided for them, and this should be separated from the dissecting bench by a low glass screen to avoid the dispersion of potentially infective material during dissection of organs. (The same separation of an 'observer area' should be applicable, on a smaller scale, in non-teaching hospitals. It can be of great value when numerous visitors enter the post-mortem room and when the individuals concerned are reluctant to put on gowns and boots.)

A room for the fixation and storage of postmortem specimens before their dissection and histological study is always needed in a teaching unit, and is an asset in any department. It should be adequately ventilated to avoid accumulation of formalin vapour. When it is desirable to store unfixed material, either for teaching or research, the provision of a cold room should also be considered.

PUBLIC MORTUARY These should be designed and equipped to at least the same standard and with the same care as hospital mortuaries. A working party has reported on standards for space and general arrangement for the Ministry of Housing and Local Government. ${ }^{1}$ In this publication stress is laid upon the siting of doors for the entrance of relatives and the entry and removal of bodies. The proper siting of the mortuary itself is important. A large amount of body storage is needed in a public mortuary (provision for at least 30 bodies is required in a unit with 1,000 necropsies per year), and there should be proper facilities for viewing of bodies, $x$-ray examination, preservation of material, and storage for clothing, together with waitingroom and W.C. for relatives. The coroner's officer should be able to interview relatives, and the needs of undertakers and police should be borne in mind. Adequate accom-

'The Planning of Mortuaries and Post Mortem Accommodation'. (1956) H.M.S.O. modation with showers and W.C.s should be available for pathologists and mortuary staff.

Special provision needs to be made for dealing with decomposed and malodorous bodies. A separate refrigerator compartment should be reserved for this type of case, and a special metal or metal-lined casket provided for body storage. Special fan-extraction of air should be provided over one post-mortem table where such bodies can be examined. It is desirable to provide a separate room for this type of case, where possible, and such a room is also useful for detailed and lengthy examinations.

\section{STATUS AND SALARIES OF MORTUARY} ATTENDANTS

The work of the permanent mortuary staff, whether in hospitals or in public mortuaries, is responsible and exacting. There has been great difficulty in recruiting suitable people for this work, and our survey leaves us in no doubt regarding the dissatisfaction of many pathologists with the status and salary scales attached to the posts concerned. In many hospitals mortuary attendants are graded as belonging to the unskilled 'porter' class, while in public mortuaries the status and salary are little better. The committee feels strongly that this is wrong, and would like to see considerable improvement in the status of mortuary attendants, and in the salary scales which apply to them. We suggest that their position in hospitals should be comparable with that of laboratory technical staff. Similar changes are necessary in public mortuaries. The superintendent of a large public mortuary, to take one example, should be comparable in status and salary with a public health inspector. Such changes, we feel, would encourage the recruitment of suitable staff, and so increase the efficiency of mortuary work. It would also make the individuals concerned less dependent on the perquisites of their officesums that come from a number of sources, not least the pocket of the pathologist whose job it is to carry out examinations in their particular post-mortem room.

\section{JOINT USE OF MORTUARIES BY HOSPITAL AND CORONERS' PATHOLOGISTS}

We have been impressed by what we regard as unnecessary duplication of mortuary facilities in some areas, and we feel that, in certain circumstances, there is scope for the joint use of mortuaries for hospital and coroners' necropsies. In big cities, the large number of coroners' necropsies makes it inevitable that these are carried out in special units and this is, in fact, desirable. But in smaller towns 
and in country areas it often appears uneconomic and inefficient to provide dual facilities for the same type of work. In some areas, it is already the practice for the hospital mortuary to be used for all coroners' necropsies from the surrounding district; in many others, conditions would appear to justify the adoption of similar units which could be designed to combine the functions of hospital and public mortuaries. Arrangements of this type need, of course, to be discussed and agreed by the coroner, the hospital authorities, and the local authority. Various administrative arrangements are in force, but the basic plan is for the local authority to pay for the use of what is, in effect, the hospital mortuary unit. This can be done either by an annual contribution or by payment for each body admitted.
Apart from the added efficiency, such a scheme caf be financially attractive, as the local authority under a statutory obligation to provide, if requested a public mortuary, and to do this properly as separate scheme can be very expensive. The size fif. a shared unit, its architectural layout, and the designation of the facilities required in it, all need careful planning by the parties concerned.

It appears to us, then, that hospitals and locat authorities might find it mutually advantageous to collaborate more regarding the joint use of mortute aries, and we feel that this topic should be the subject of their joint discussion, following the approval of the coroner, whenever the provision of a new mortuary unit-either hospital or public-io is considered. 